\title{
Recovery of Gallium from Corundum Flue Dust by Two-Stage Alkali Leaching, Carbonation, Acid Leaching and Solvent Extraction Process
}

\author{
Kang Wen ${ }^{1}$, Feng Jiang ${ }^{1}$, Xiangyang Zhou ${ }^{2, *}$ and Zhaoming Sun ${ }^{2}$ \\ 1 School of Materials Science and Engineering, Central South University, Changsha 410083, China; \\ okafor85@hotmail.com (K.W.); jfeng2@csu.edu.cn (F.J.) \\ 2 Institute of Light Metals and Industrial Electrochemistry, School of Metallurgy and Environment, \\ Central South University, Changsha 410083, China; szm20050729@163.com \\ * Correspondence: xyzhou@csu.edu.cn; Tel.: +86-731-8883-6329
}

Received: 21 June 2018; Accepted: 14 July 2018; Published: 17 July 2018

\begin{abstract}
Flue dust generated during the process of manufacturing corundum is a carrier of critical metal gallium. In this study, a process of alkali leaching-carbonation-acid leaching-solvent extraction was developed to recover and enrich gallium from corundum flue dust. Over $93 \%$ of the gallium in corundum flue dust could be recovered through a two-stage alkali leaching process, which consists of 120 min of concentrated alkali leaching in $\mathrm{NaOH}$ solution and a subsequent 30-min dilute alkali leaching (after dilution), with an alkali-to-ore mass ratio of 1.2:1. Liquid to solid ratios in two alkali leaching stages were 1.5:1 and 8:1, respectively. The carbonation process was employed to remove high-level $\mathrm{Si}$ in alkali leachate. After carbonation and $\mathrm{HCl}$ leaching, over $96 \%$ of gallium in the $\mathrm{NaOH}$ leachate could be dissolved into acid solution. After extracting gallium from the $\mathrm{HCl}$ leachate using $\mathrm{N} 235$ as extracting agent, $1 \% \mathrm{NaOH}$ solution was used to strip gallium from the organic phase. The extraction and stripping efficiency of gallium was over $99 \%$ and $97 \%$, respectively.
\end{abstract}

Keywords: gallium; corundum flue dust; alkali leaching; carbonation; solvent extraction

\section{Introduction}

The application of gallium in modern electronic devices, such as integrated circuits (ICs), photovoltaic (PV), and light emitting diodes (LED), was promoted because some gallium compounds showed special properties when exposed to the light spectrum [1]. Nowadays, the global demand for gallium is growing as the demand for Ga-based products continues to increase.

Gallium is a scarce, but not rare element. It is widely distributed in nature, and its content in the earth's crust is estimated at about 15-19 ppm, which is higher than arsenic, antimony, silver, bismuth, molybdenum, and tungsten, among others [2,3]. However, gallium has little tendency to be naturally concentrated. High-gallium minerals are extremely rare and gallium produced from these sources is very limited. Gallium is always obtained as a byproduct from processing of ores for other metals and effluent streams in metal production or power plants. Besides, gallium is also recycled from scrap generated in the process of manufacturing GaAs- and GaN-based devices. During the past few decades, studies have been carried out on recovering gallium from various sources, which included Bayer liquor [4-6], aluminum industry residues [7], coal fly ash [8,9], industrial zinc or copper processing residues [2,10-12], phosphorus flue dust [13], and corundum slags, among others [14]. In addition, flue dust generated from the process of producing brown corundum was also found to be an important source of gallium, because the gallium content in it was relatively high. Methods have been proposed to extract gallium from corundum flue dust, including hydrochloric acid leaching-solvent extraction [15], potassium and calcium salt roasting-alkali leaching [16], and dilute 
sulfuric acid leaching-extraction [17]. However, these methods have their own disadvantages. Using $\mathrm{HCl}$ leaching-solvent extraction method could only recover $70 \%$ of the gallium in corundum flue dust; the leaching efficiency is low. The roasting-alkali leaching method requires high roasting temperature (over $1200{ }^{\circ} \mathrm{C}$ ), inevitably leading to high energy consumption. The dilute $\mathrm{H}_{2} \mathrm{SO}_{4}$ leaching-extraction method can extract over $80 \%$ of the gallium in corundum flue dust under atmospheric pressure, but it has the problem of low filter velocity in the case of leaching high-silica flue dust because of the formation of silica gel. Moreover, in some former studies, extractant such as amines, tri-C8-10-alkyl (N235), N, N-di(1-Methyl heptyl) acetamide (N503), and tributyl phosphate (TBP), among others, were applied to extract $\mathrm{Ga}^{3+}$ and $\mathrm{In}^{3+}$ from chloride medium [18,19]; and in this study, N235 was used to extract $\mathrm{Ga}^{3+}$ from the $\mathrm{HCl}$ leachate.

Based on former studies, this study aimed to develop an effective and efficient method to recover and enrich gallium from a corundum flue dust containing a high level of silica. This method consisted of alkali leaching, total carbonation, acid leaching, and solvent extraction. The recovery efficiency of gallium was over $90 \%$ and the entire process was performed under mild conditions.

\section{Materials and Methods}

\subsection{Materials and Reagents}

The corundum flue dust used in this study was collected from Shanxi province, China. Chemical composition of this corundum flue dust was shown in Table 1. All chemical reagents were used as received without further purification. Sodium hydroxide, hydrochloric acid used for leaching, and kerosene, 1-decanol used for solvent extraction were of analytical grade. N235 (with carbon chains C8 $35-45 \%$ and C10 52-63\%, Shanghai Rare-Earth Chemical Co. Ltd., Shanghai, China) used for solvent extraction was of technical grade.

Table 1. Chemical composition of the corundum flue dust (wt. \%).

\begin{tabular}{cc}
\hline Compounds and Elements & Content/wt. \% \\
\hline $\mathrm{MgO}$ & 0.26 \\
$\mathrm{CaO}$ & 0.13 \\
$\mathrm{Fe}_{2} \mathrm{O}_{3}$ & 3.52 \\
$\mathrm{Al}_{2} \mathrm{O}_{3}$ & 18.97 \\
$\mathrm{SiO}_{2}$ & 56.65 \\
$\mathrm{Ga}$ & 0.15 \\
$\mathrm{~K}_{2} \mathrm{O}$ & 4.39 \\
$\mathrm{Na}_{2} \mathrm{O}$ & 1.36 \\
Loss on ignition & 14.22 \\
\hline
\end{tabular}

\subsection{Experimental Procedure}

\subsubsection{Leaching}

The alkali leaching process in this study consisted of two stages: concentrated alkali leaching and diluted alkali leaching (as shown in Figure 1).

First, the corundum flue dust was mixed with $\mathrm{NaOH}$ solution. Leaching tests were performed in a $5 \mathrm{~L}$ Teflon container with a lid, and the suspension was agitated constantly. Waterbath equipment (DK-S28, Jiwei Test, Shanghai, China) was used to keep a constant temperature of suspension during the entire process. After a preset reaction time, a certain amount of water was added to dilute the suspension, and the suspension was continuously stirred for $30 \mathrm{~min}$. 


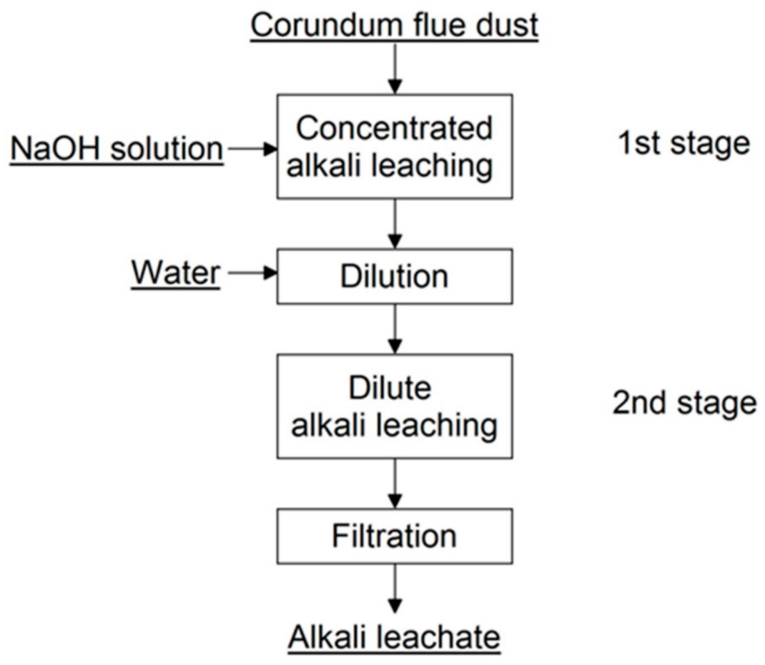

Figure 1. Flowchart of the two-stage alkali leaching process.

In order to determine the optimum conditions for alkali leaching of gallium from corundum flue dust, leaching parameters such as alkali-to-ore mass ratio, leaching temperature, reaction time, and liquid to solid ratio were investigated. In the tests, the mass ratio of alkali to ore was set from 0.8 to 1.8; the leaching temperature was tested from $50^{\circ} \mathrm{C}$ to $90^{\circ} \mathrm{C}$; reaction time for the first alkali leaching stage was set from 60 to $180 \mathrm{~min}$; liquid to solid ratios for the two alkali leaching stages were set from 1.5:1 to 3.5:1 and 5:1 to 10:1, respectively. The duration of the second alkali leaching stage (dilute alkali leaching) was fixed at $30 \mathrm{~min}$. Main reactions occurred during the leaching process are listed in (1)-(3):

$$
\begin{gathered}
\mathrm{SiO}_{2}+2 \mathrm{NaOH} \rightarrow \mathrm{Na}_{2} \mathrm{SiO}_{3}+\mathrm{H}_{2} \mathrm{O} \\
\mathrm{Al}_{2} \mathrm{O}_{3}+2 \mathrm{NaOH}+3 \mathrm{H}_{2} \mathrm{O} \rightarrow 2 \mathrm{Na}\left[\mathrm{Al}(\mathrm{OH})_{4}\right] \\
\mathrm{Ga}_{2} \mathrm{O}_{3}+2 \mathrm{NaOH}+3 \mathrm{H}_{2} \mathrm{O} \rightarrow 2 \mathrm{Na}\left[\mathrm{Ga}(\mathrm{OH})_{4}\right]
\end{gathered}
$$

The leaching efficiency was calculated according to Equation (4):

$$
\text { Leaching efficiency }(\%)=\left(m_{1} / m_{2}\right) \times 100 \%
$$

where $m_{1}$ is the mass of metal leached, and $m_{2}$ is the mass of metal contained in raw materials.

After alkali leaching, the leachate was transferred into a container with agitator and was agitated continuously. $\mathrm{CO}_{2}$ was introduced into the alkali leachate until $\mathrm{pH}$ value of the solution dropped to 9 (Temperature of $90{ }^{\circ} \mathrm{C}, \mathrm{CO}_{2}$ flow of $20 \mathrm{~mL} / \mathrm{min}$ ). After filtration, the carbonated precipitate was washed three times with boiling water to remove $\mathrm{Na}^{+}$. Then, the gallium-enriched precipitate obtained from the carbonation process was leached with $4 \mathrm{~mol} / \mathrm{L}$ hydrochloric acid. The final filter cake was washed successively with diluted hydrochloric acid and water, and then it was dried overnight in an oven at $60^{\circ} \mathrm{C}$.

In the process of leaching, the liquid to solid ratio $(L / S)$ was defined in Equation (5):

$$
(L / S)_{i}=V_{i} / m(i=1,2)
$$

In this study, liquid to solid ratios $(L / S)$ in the first and second alkali leaching stages were designated as $(L / S)_{1}$ and $(L / S)_{2}$, respectively. $V_{1}(\mathrm{~mL})$ is the volume of water added in the first alkali leaching stage (i.e., concentrated alkali leaching stage), $V_{2}(\mathrm{~mL})$ is the total volume of water added in both two stages of alkali leaching (including $V_{1}$ and the volume of water added later to dilute the suspension), and $m(\mathrm{~g})$ is the mass of corundum flue dust. 


\subsubsection{Solvent Extraction}

The $\mathrm{HCl}$ leachate should be evaporated to about half volume to increase its acidity. The solvent extraction process was carried out by mixing the concentrated $\mathrm{HCl}$ leachate with the organic phase ( 25 vol. \% N235 + 5 vol. \% 1-decanol +70 vol. \% kerosene) and agitating for $15 \mathrm{~min}$, at an aqueous to organic phase volume ratio $(\mathrm{A} / \mathrm{O})$ of 4.5:1. Then, gallium was stripped from the organic phase with $1 \% \mathrm{NaOH}$ solution $(\mathrm{A} / \mathrm{O}=1: 1)$. The solvent extraction process was performed at room temperature.

\subsection{Analysis Method}

Composition of this corundum flue dust was determined by X-ray fluorescence spectroscopy (XRF) (EDXL 300, Rigaku, Tokyo, Japan). The X-ray diffraction (XRD) technique (TTRIII, Rigaku, Tokyo, Japan) was used to identify phases in the flue dust (with $\mathrm{Cu} \mathrm{K} \alpha$ radiation, scan step of $10^{\circ} / \mathrm{min}$, 20-range of $10-70^{\circ}$ ). The particle size of the flue dust sample was analyzed using a particle size analyzer (Mastersizer 2000, Malvern Panalytical, Malvern, UK) and the statistical result was obtained. The content of elements in solution was analyzed using inductivity coupled plasma atomic emission spectroscopy (IRIS Intrepid II XSP ICP-AES, Thermo Fisher Scientific, Waltham, MA, USA).

\section{Results and Discussion}

\subsection{Characterization of Corundum Flue Dust}

The XRD pattern of the corundum flue dust sample used in this study is shown in Figure 2.

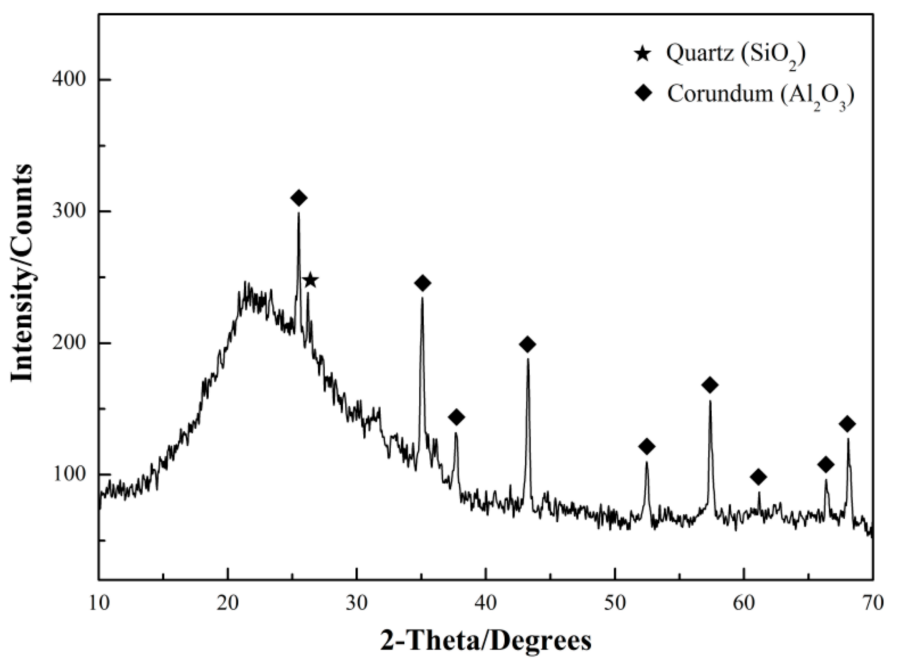

Figure 2. X-ray diffraction (XRD) pattern of the corundum flue dust.

As shown in Table 1, the content of gallium in this flue dust was $0.15 \mathrm{wt}$. \%, which was much higher than that in bauxite, and the silica content was over $50 \mathrm{wt}$. \%. Figure 2 shows that the main phases in this flue dust were corundum and quartz, and broad scattered peaks in this pattern indicate that the majority of silica phase in this flue dust were amorphous silica. Former studies indicated that gallium in the corundum flue dust exists as $\mathrm{Ga}_{2} \mathrm{O}_{3}$ in vitreous eutectic mixtures [20].

Particle size distribution of this flue dust sample is illustrated in Figure 3. Based on the transport phenomenon, decreasing particle sizes of ores could increase leaching efficiency of metals. This was because the creation of high specific area increases the chance of contacts between leaching agent and ore particles, consequently facilitating the diffusion of reactants and the reaction products. In this study, the corundum flue dust particles are fine; about $85 \%$ of the flue dust particles were finer than $100 \mu \mathrm{m}$, and nearly $93 \%$ of the particles were finer than $200 \mu \mathrm{m}$. Moreover, the cost of sieving and 
grinding would be unfavorable for scale-up tests in the future. Therefore, in this study, corundum flue dust was used in tests without sieving and grinding.

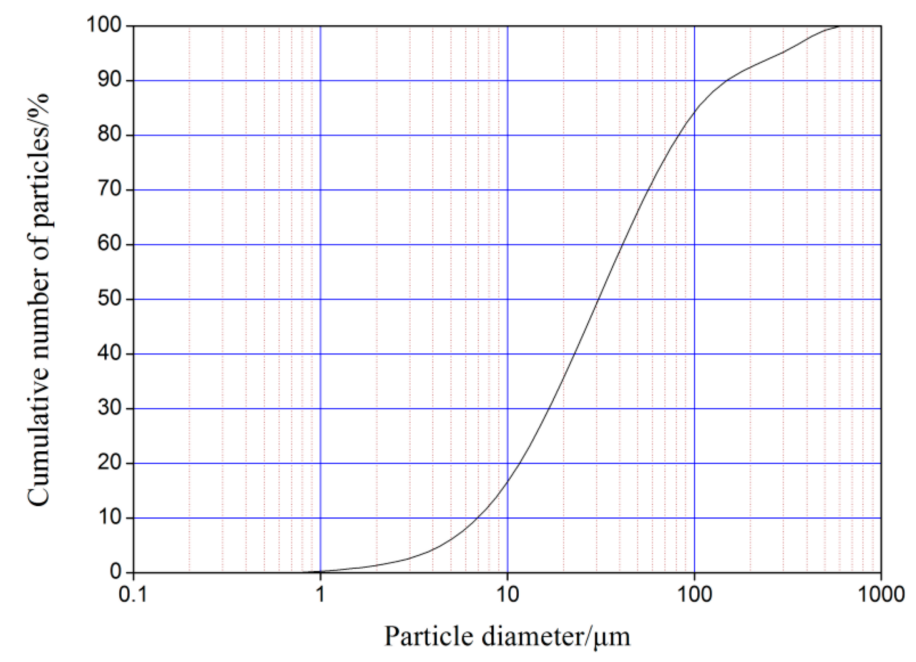

Figure 3. Particle size distribution of corundum flue dust.

\subsection{Alkali Leaching}

\subsubsection{Effect of Alkali-to-Ore Mass Ratio}

Figure 4 shows the results of leaching tests performed under different alkali-to-ore mass ratios.

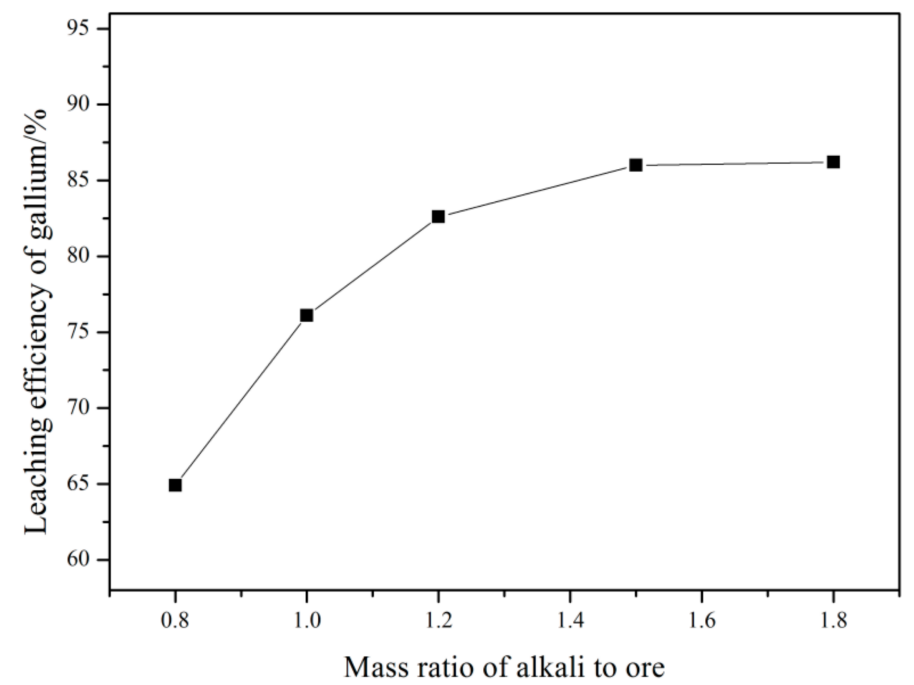

Figure 4. Effect of alkali-to-ore mass ratio on leaching efficiency of gallium.

Flue dust was leached for 60 min in concentrated $\mathrm{NaOH}$ solution (the initial $\mathrm{NaOH}$ concentration were 35 wt. $\%, 40$ wt. $\%, 44$ wt. $\%, 50$ wt. $\%$, and 55 wt. $\%$ at alkali-to-ore mass ratios of $0.8,1.0,1.2,1.5$, and 1.8 , respectively) at $90{ }^{\circ} \mathrm{C}$, followed by a 30-min leaching process after dilution, with $(L / S)_{1}=1.5: 1$ and $(L / S)_{2}=6: 1$. As illustrated in Figure 4 that the leaching efficiency of gallium increased obviously from $64.9 \%$ to $82.6 \%$ with a rising alkali-to-ore mass ratio from 0.8 to 1.2 , indicating that the amount of $\mathrm{NaOH}$ was important for gallium recovery. Further increasing the alkali-to-ore mass ratio to 1.8 could only raise the gallium leaching efficiency slightly to $86.2 \%$. Therefore, an alkali-to-ore mass ratio of 1.2 was considered appropriate in this study. 


\subsubsection{Effect of Leaching Temperature}

The effect of temperature on alkali leaching is shown in Figure 5.

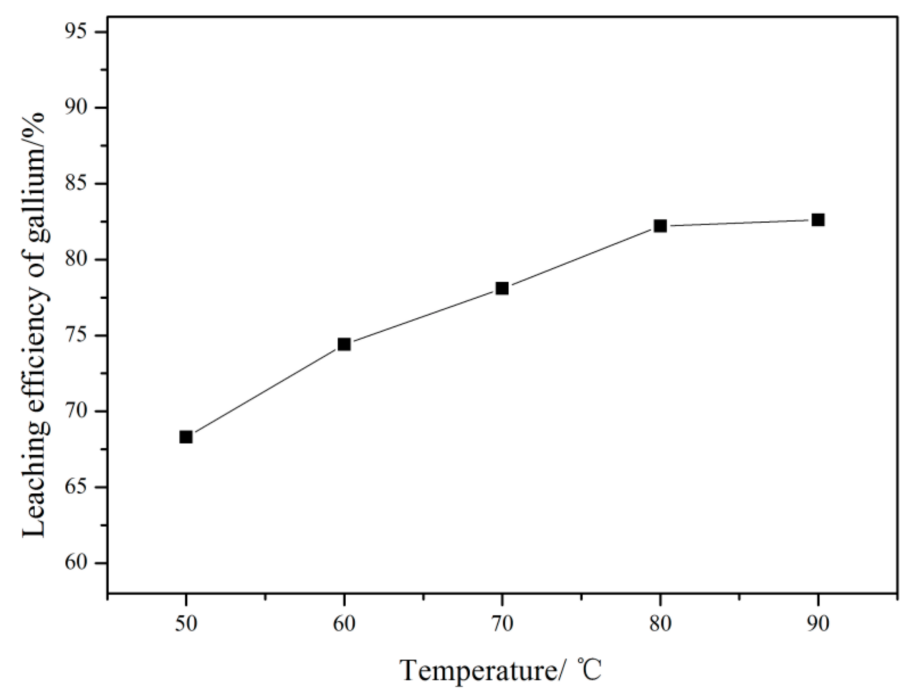

Figure 5. Effect of temperature on leaching efficiency of gallium.

In this set of tests, leaching temperature was varied in the range between 50 and $90{ }^{\circ} \mathrm{C}$, and the mass ratio of alkali to ore was fixed at 1.2:1. Other test parameters were set the same as in Section 3.2.1. As shown in Figure 5, the leaching efficiency of gallium shows an upward trend as the temperature raised. At a temperature of $80^{\circ} \mathrm{C}, 82.2 \%$ of the gallium in flue dust could be extracted. The leaching efficiency of gallium was maintained almost constant when the temperature was increased to $90^{\circ} \mathrm{C}$. Therefore, the subsequent leaching tests were performed at $80^{\circ} \mathrm{C}$.

\subsubsection{Effect of Reaction Time of the First Alkali Leaching Stage (Concentrated Alkali Leaching Stage)}

Figure 6 shows the variation of gallium leaching efficiency with increased reaction time for concentrated alkali leaching.

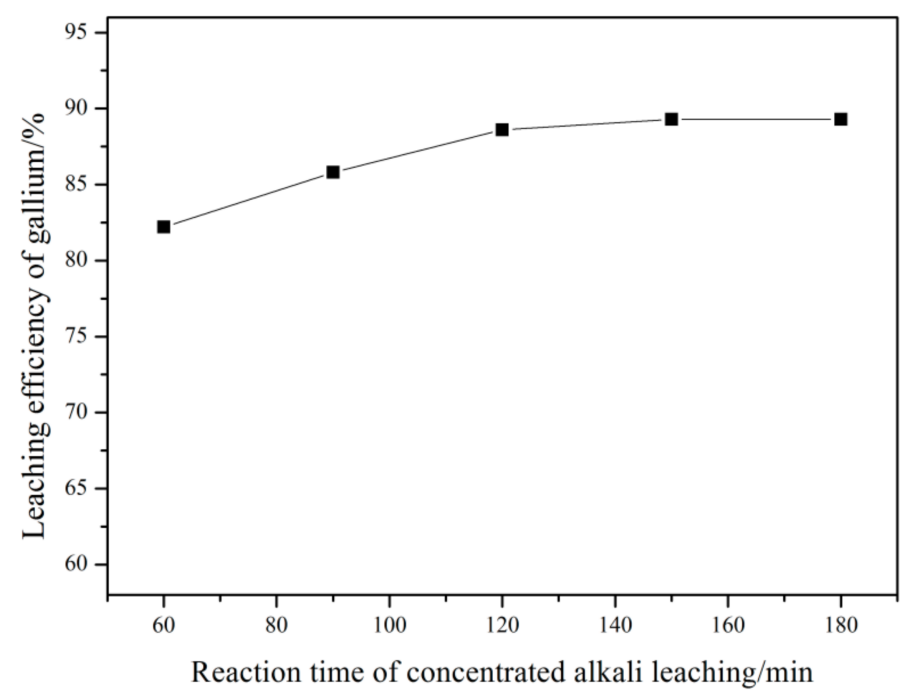

Figure 6. Effect of reaction time on leaching efficiency of gallium. 
This set of leaching tests was performed at $80^{\circ} \mathrm{C}$, with an alkali-to-ore mass ratio of 1.2:1, $(L / S)_{1}=$ 1.5:1 and $(L / S)_{2}=6: 1$. As shown in Figure 6, the leaching efficiency of gallium increased steadily from $82.2 \%$ to $88.6 \%$ with prolongation of reaction time from 60 to $120 \mathrm{~min}$. This was because as the reaction time increased, more surface area of the unreacted particles could come into contact with the leaching agent. However, the leaching efficiency of gallium remained almost constant when the reaction time was further prolonged, indicating that the leaching reaction achieved its reaction equilibrium within $120 \mathrm{~min}$. According to this, a reaction time of $120 \mathrm{~min}$ was considered enough for the first alkali leaching stage.

\subsubsection{Effect of $(L / S)_{1}(L / S$ for Concentrated Alkali Leaching)}

The effect of $L / S$ for the concentrated alkali leaching on recovery of gallium was shown in Figure 7 . $L / S$ for concentrated alkali leaching varied from 1.5 to 3.5 in this set of experiments. Leaching tests were performed at $80^{\circ} \mathrm{C}$. The reaction times for two alkali leaching stages were $120 \mathrm{~min}$ and $30 \mathrm{~min}$, respectively. The mass ratio of alkali to ore was 1.2:1, and $L / S$ for the second alkali leaching stage (dilute alkali leaching) was 6:1. As shown in Figure 7, the leaching efficiency of gallium decreased significantly with the increase of $L / S$ in the concentrated alkali leaching stage, and it dropped to $74.5 \%$ at the $L / S$ of 3.5:1. It is obvious that lower $L / S$ value in the first alkali leaching stage was beneficial to the leaching of gallium from flue dust. According to the test results, a liquid to solid ratio of 1.5:1 was optimal for concentrated alkali leaching.

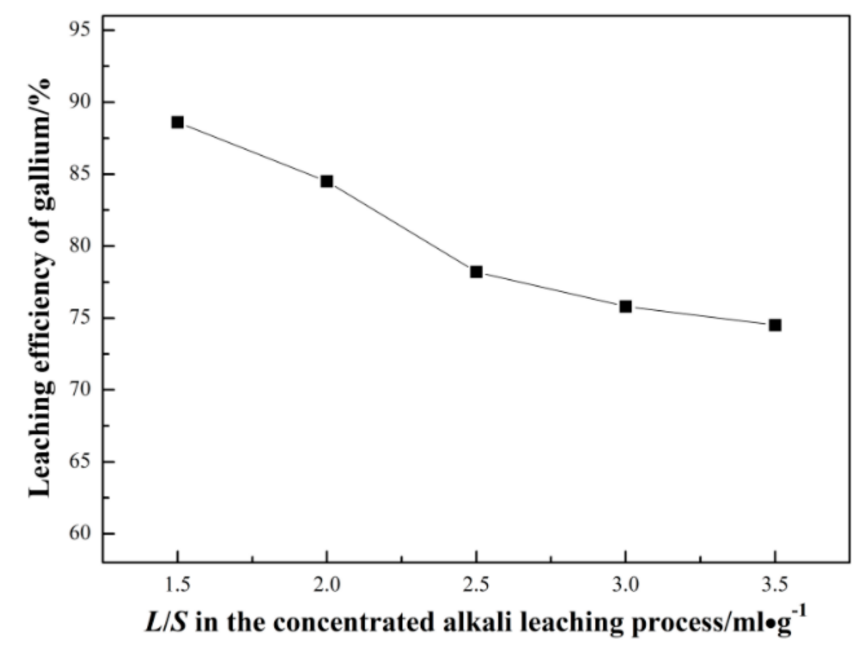

Figure 7. Effect of liquid to solid $(L / S)$ for concentrated alkali leaching on leaching efficiency of gallium.

\subsubsection{Effect of $(L / S)_{2}(L / S$ for Dilute Alkali Leaching)}

Figure 8 shows the variation tendency of gallium leaching efficiency with the increase of $L / S$ value in dilute alkali leaching stage.

$L / S$ in the second alkali leaching stage was varied in the range from $5: 1$ to $10: 1$ to investigate its effect on gallium recovery. In these tests, $L / S$ for the first alkali leaching stage (concentrated alkali leaching) was fixed at 1.5:1, and other testing parameters including leaching temperature, reaction time, and alkali-to-ore mass ratio were the same as those in Section 3.2.4. Figure 8 shows that a higher $L / S$ value in the dilute alkali leaching stage was more favorable for gallium recovery and the leaching efficiency of gallium reached $93.6 \%$ at the $L / S$ of $8: 1$. At a higher $L / S$ value of $10: 1$, the leaching efficiency of gallium was about $94 \%$. Therefore, in the second stage of alkali leaching, a $L / S$ of 8:1 was considered to be optimal in this study. 


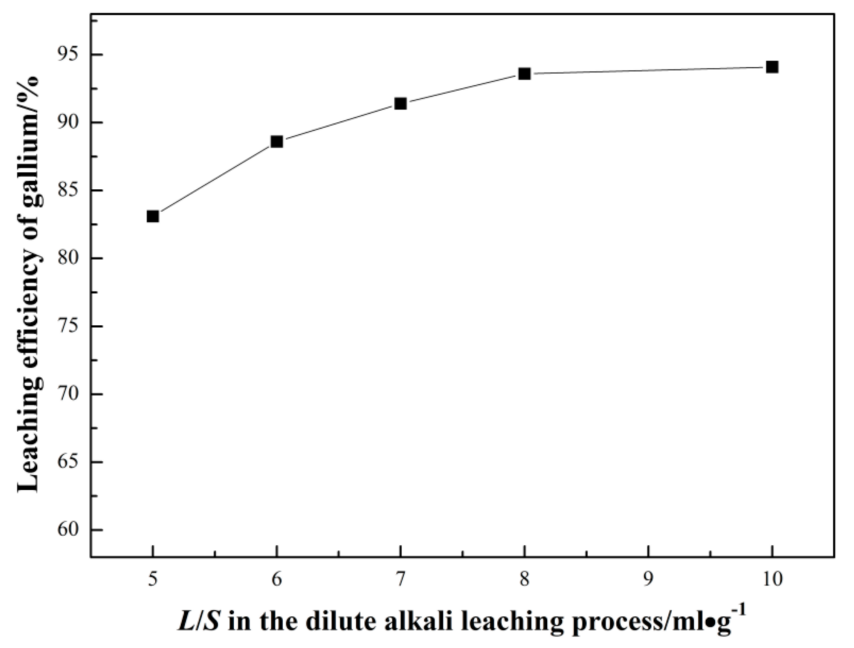

Figure 8. Effect of $L / S$ for dilute alkali leaching on leaching efficiency of gallium.

According to the results shown above, the $L / S$ value in two alkali leaching stages significantly affected the leaching efficiency of gallium. A low $L / S$ value in the first leaching stage implied that the concentration of $\mathrm{NaOH}$ in suspension was high, and this was conducive to the corrosion of phases (especially silica-enriched phases) in the flue dust; hence, gallium could be easily dissolved into the suspension. However, high viscosity (implied poor fluidity) of the concentrated alkali suspension was unfavorable for filtration and the further leaching of gallium. Therefore, the concentrated suspension should be diluted. Optimal conditions for the two-stage alkali leaching are shown in Table 2.

Table 2. Optimal conditions and result for two-stage alkali leaching. ( $L / S$-liquid to solid ratio).

\begin{tabular}{cc}
\hline Test Parameters and Result & Value \\
\hline Alkali-to-ore mass ratio & $1.2: 1$ \\
Temperature & $80{ }^{\circ} \mathrm{C}$ \\
Reaction Time (1st + 2nd stage) & $120 \mathrm{~min}+30 \mathrm{~min}$ \\
$L / S$ for the 1st alkali leaching stage & $1.5: 1$ \\
$L / S$ for the 2nd alkali leaching stage & $8: 1$ \\
Leaching efficiency & $93.6 \%$ \\
\hline
\end{tabular}

\subsection{Carbonation and Acid Leaching}

The concentration of Si in the alkali leachate was high (>15 g/L), which was unfavorable for further treatment of the leachate. As a result, leachate obtained from the alkali leaching process should be carbonated first. Main reactions during the process of carbonation are as described in Equations (6)-(10) [21].

$$
\begin{gathered}
2 \mathrm{NaOH}+\mathrm{CO}_{2} \rightarrow \mathrm{Na}_{2} \mathrm{CO}_{3}+\mathrm{H}_{2} \mathrm{O} \\
\mathrm{Na}_{2} \mathrm{CO}_{3}+\mathrm{CO}_{2}+\mathrm{H}_{2} \mathrm{O} \rightarrow 2 \mathrm{NaHCO}_{3} \\
\mathrm{Na}_{2} \mathrm{SiO}_{3}+\mathrm{CO}_{2}+\mathrm{nH}_{2} \mathrm{O} \rightarrow \mathrm{Na}_{2} \mathrm{CO}_{3}+\mathrm{SiO}_{2} \cdot \mathrm{nH}_{2} \mathrm{O} \\
2 \mathrm{Na}\left[\mathrm{Al}(\mathrm{OH})_{4}\right]+\mathrm{CO}_{2} \rightarrow 2 \mathrm{Al}(\mathrm{OH})_{3} \downarrow+\mathrm{Na}_{2} \mathrm{CO}_{3}+\mathrm{H}_{2} \mathrm{O} \\
2 \mathrm{Na}\left[\mathrm{Ga}(\mathrm{OH})_{4}\right]+4 \mathrm{NaHCO}_{3}+\mathrm{aq} \rightarrow \mathrm{Na}_{2} \mathrm{O} \cdot \mathrm{Ga}_{2} \mathrm{O}_{3} \cdot 2 \mathrm{CO}_{2} \cdot \mathrm{nH}_{2} \mathrm{O}+2 \mathrm{Na}_{2} \mathrm{CO}_{3}+(6-\mathrm{n}) \mathrm{H}_{2} \mathrm{O}+\mathrm{aq}
\end{gathered}
$$

After being washed with boiling water, the carbonated precipitate was leached by $4 \mathrm{~mol} / \mathrm{L} \mathrm{HCl}$. The analysis results show that there was hardly any gallium in both carbonated liquor and the washing liquor, the recovery efficiency of gallium in the process of carbonation was higher than $99 \%$. Over $96 \%$ of gallium in carbonated precipitate could be dissolved into the $\mathrm{HCl}$ leachate. $\mathrm{Si}$ in the alkali leachate 
was effectively removed via carbonation and acid leaching; the concentration of $\mathrm{Si}$ in the $\mathrm{HCl}$ leachate was reduced to lower than $50 \mathrm{mg} / \mathrm{L}$. As gallium in the flue dust was transferred into the acid leachate, hydrated silica could also be obtained.

\subsection{Solvent Extraction}

The acid leachate obtained from the alkali leaching-carbonation- $\mathrm{HCl}$ leaching process was evaporated to half of its volume to ensure sufficient acidity, so that gallium ions in the solution converted to gallium tetrachloride $\mathrm{GaCl}_{4}{ }^{-}$ions [22]. N235 was chosen as extracting agent in this study, and the organic phase consisted of 25 vol. \% N235, 5 vol. \% 1-decanol, and 70 vol. \% kerosene. The process of solvent extraction can be described as follows [23-26].

$$
\begin{gathered}
\mathrm{R}_{3} \mathrm{~N}+\mathrm{HCl} \rightleftharpoons \mathrm{R}_{3} \mathrm{NH}^{+} \mathrm{Cl}^{-} \\
\mathrm{Ga}^{3+}+4 \mathrm{Cl}^{-} \rightleftharpoons \mathrm{GaCl}_{4}^{-} \\
\mathrm{Fe}^{3+}+4 \mathrm{Cl}^{-} \rightleftharpoons \mathrm{FeCl}_{4}^{-} \\
\mathrm{R}_{3} \mathrm{NH}^{+} \mathrm{Cl}^{-}+\mathrm{GaCl}_{4}^{-} \rightleftharpoons \mathrm{R}_{3} \mathrm{NH}^{+} \mathrm{GaCl}_{4}^{-}+\mathrm{Cl}^{-} \\
\mathrm{R}_{3} \mathrm{NH}^{+} \mathrm{Cl}^{-}+\mathrm{FeCl}_{4}^{-} \rightleftharpoons \mathrm{R}_{3} \mathrm{NH}^{+} \mathrm{FeCl}_{4}{ }^{-}+\mathrm{Cl}^{-}
\end{gathered}
$$

Gallium in the solution was extracted as $\mathrm{GaCl}_{4}^{-}$[25-27], as shown in Equation (13). The concentration of major elements in the acid leachate after evaporation is shown in Table 3. The results of solvent extraction are shown in Table 4. The extraction efficiency of gallium was higher than $99 \%$ in a two-stage counter-current extraction process with $\mathrm{A} / \mathrm{O}$ (aqueous/organic volume ratio) $=4.5: 1$, and the stripping efficiency of gallium was higher than $97 \%$ when the organic phase was stripped with $1 \% \mathrm{NaOH}$ solution in a three-stage counter-current stripping process $(\mathrm{A} / \mathrm{O}=1: 1)$. In addition, the extraction and stripping efficiencies of iron were about $99 \%$ and $96 \%$, respectively. In the process of solvent extraction, tertiary amine only extracted $\mathrm{Ga}^{3+}$ and $\mathrm{Fe}^{3+}$ in leachate, while $\mathrm{Al}^{3+}$ remained in the raffinate [22,28]. As a result, major elements in the strip solution were gallium and iron, and the concentrations of Ga and Fe in this solution were about $2 \mathrm{~g} / \mathrm{L}$ and $1 \mathrm{~g} / \mathrm{L}$, respectively.

Table 3. Content of major elements in acid leachate after evaporation $(\mathrm{g} / \mathrm{L})$.

\begin{tabular}{cc}
\hline Element & Concentration/wt. \% \\
\hline $\mathrm{Ga}$ & 0.468 \\
$\mathrm{Si}$ & 0.110 \\
$\mathrm{Al}$ & 1.823 \\
$\mathrm{Fe}$ & 0.244 \\
\hline
\end{tabular}

Table 4. Recovery of gallium from the acid leachate. (A/O-aqueous/organic volume ratio)

\begin{tabular}{cc}
\hline Test Parameters and Results & Value \\
\hline Extraction & - \\
Solvent & $25 \%$ N235 $+5 \%$ 1-Decanol $+70 \%$ kerosene \\
A $/ \mathrm{O}$ & $4.5: 1$ \\
Temperature & Ambient temperature \\
Extraction efficiency (Ga) & $99.8 \%$ \\
Extraction efficiency (Fe) & $99.1 \%$ \\
Stripping & - \\
Stripping agent & $1 \%$ NaOH solution \\
A /O & $1: 1$ \\
Temperature & Ambient temperature \\
Stripping efficiency (Ga) & $97.4 \%$ \\
Stripping efficiency (Fe) & $96.5 \%$ \\
\hline
\end{tabular}


Obviously, gallium in corundum flue dust could be effectively recovered and concentrated through leaching and extraction processes in this study, which facilitated further separation and purification of gallium. Separation of gallium from the strip solution could be achieved by further processing the strip solution with conventional methods. For instance, gallium could be extracted individually from the solution (containing both $\mathrm{FeCl}_{3}$ and $\mathrm{GaCl}_{3}$ ) after reducing $\mathrm{Fe}^{3+}$ to $\mathrm{Fe}^{2+}$ [22].

\section{Conclusions}

Gallium was effectively recovered and enriched from the corundum flue dust by performing a process consisting of alkali leaching, carbonation, acid leaching, and solvent extraction. The flowchart is given in Figure 9.

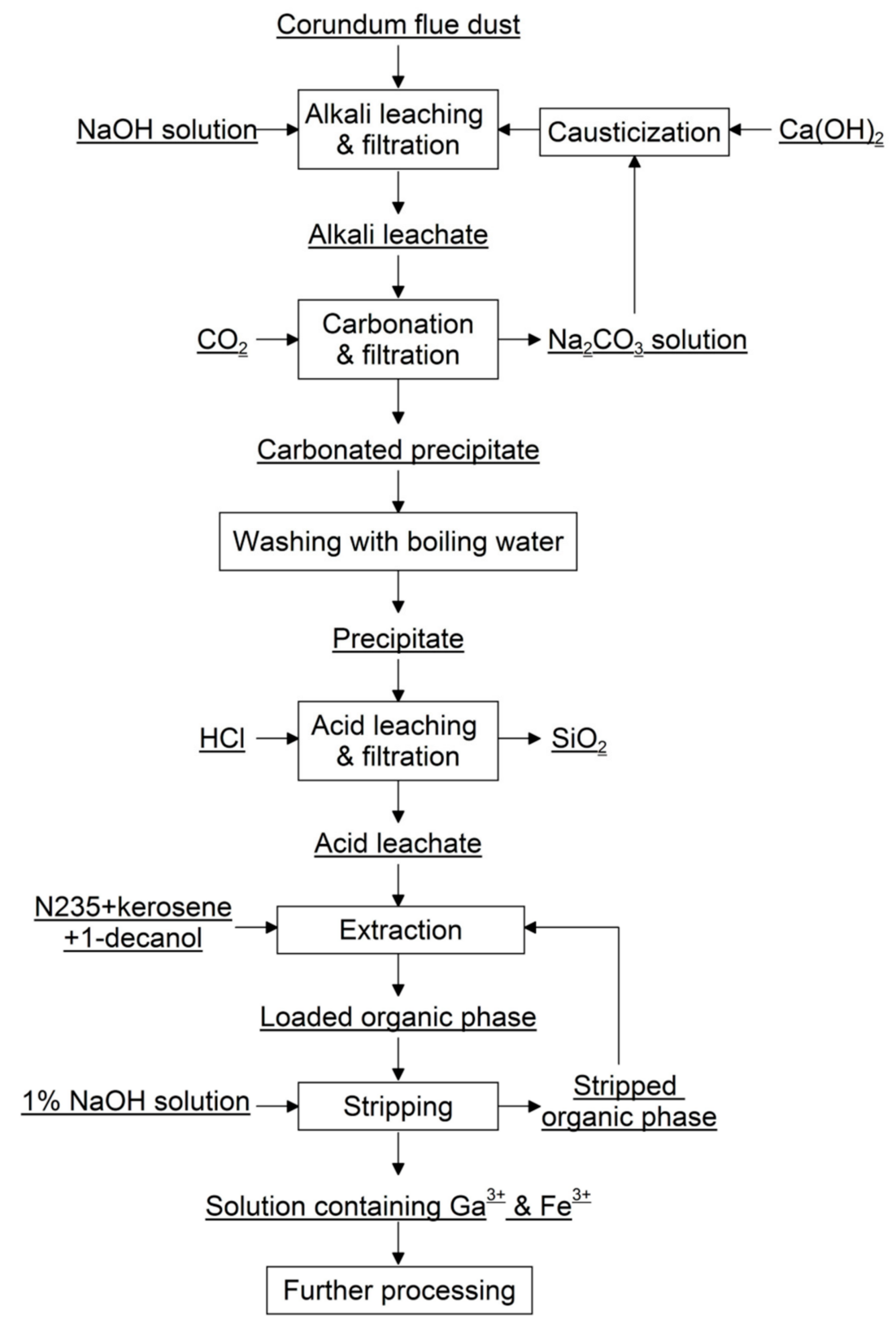

Figure 9. Flowchart for the process of gallium recovery.

The leaching efficiency of gallium in the two-stage alkali leaching process was above $93 \%$ under optimum conditions, including alkali-to-ore mass ratio of $1.2: 1$; temperature of $80{ }^{\circ} \mathrm{C}$; reaction time 
of $120 \mathrm{~min}+30 \mathrm{~min}$; and liquid to solid ratios of 1.5:1 and 8:1 in the first and second alkali leaching stage, respectively. During the process of carbonation and $\mathrm{HCl}$ leaching, over $96 \%$ of gallium in the alkali leachate could be extracted into $\mathrm{HCl}$ leachate; high-level $\mathrm{Si}$ in the solution could also be effectively removed.

Using a mixture of 25 vol. \% N235, 5 vol. \% 1-Decanol, and 70 vol. \% kerosene (with A/O = 4.5:1), $99.8 \%$ of the gallium in $\mathrm{HCl}$ leachate could be extracted. Then, the loaded organic phase was stripped with $1 \% \mathrm{NaOH}$ solution at an $\mathrm{A} / \mathrm{O}$ ratio of $1: 1$, and the stripping efficiency of gallium was $97.4 \%$. As a result of these, a gallium-enriched solution containing $2 \mathrm{~g} / \mathrm{L} \mathrm{Ga}$ and $1 \mathrm{~g} / \mathrm{L}$ Fe was obtained.

The method proposed in this study contributed to recycling of rare metal gallium from a common industrial waste-corundum flue dust. It was easy to operate, and had advantages of high recovery efficiency of gallium and low energy consumption.

Author Contributions: X.Z. collected the flue dust sample in Shanxi Province; X.Z. and F.J. designed the experiments; K.W. performed the experiments and wrote this paper; Z.S. analyzed the data; all authors contributed to the discussion.

Funding: This research received no external funding.

Acknowledgments: This study was financially supported by the National Natural Science Foundation of China (51274240 and 51204209) and the international cooperation major Project of Ministry of Science and Technology of the People's Republic of China (2006DFA53240). And we would like to thank Mr. Hongzhuan Liu, for technical support with experiments.

Conflicts of Interest: The authors declare no conflict of interest.

\section{References}

1. Gallium-A Smart Metal. Available online: https://pubs.usgs.gov/fs/2013/3006/ (accessed on 13 July 2018).

2. Gray, F.; Kramer, D.; Bliss, J. Gallium and Gallium Compounds. In Kirk-Othmer Encyclopedia of Chemical Technology, 5th ed.; Kirk-Othmer, R., Ed.; VCH: New York, NY, USA, 2005; Volume 12, pp. 337-364.

3. Naumov, A. Status and prospects of world gallium production and the gallium market. Metallurgist 2013, 57, 367-371. [CrossRef]

4. Lu, X.; Wang, L.; Wang, X.; Niu, X. Research progress in gallium recovery technology. Nonferrous Met. 2008, 60, 105-108.

5. Zhao, Z.; Yang, Y.; Xiao, Y.; Fan, Y. Recovery of gallium from Bayer liquor: A review. Hydrometallurgy 2012, 125, 115-124. [CrossRef]

6. Vind, J.; Alexandri, A.; Vassiliadou, V.; Panias, D. Distribution of selected trace elements in the bayer process. Metals 2018, 8, 327. [CrossRef]

7. Carvalho, M.; Neto, K.; Nobrega, A.; Medeiros, J. Recovery of gallium from aluminum industry residues. Sep. Sci. Technol. 2000, 35, 57-67. [CrossRef]

8. Gutierrez, B.; Pazos, C.; Coca, J. Recovery of gallium from coal fly ash by a dual reactive extraction process. Waste Manag. Res. 1997, 15, 371-382. [CrossRef]

9. Zou, J.; Tian, H.; Wang, Z. Leaching process of rare earth elements, gallium and niobium in a coal-bearing strata-hosted rare metal deposit-A study from the late Permian tuff in the Zhongliangshan Mine, Chongqing. Metals 2017, 7, 174. [CrossRef]

10. Wu, X.; Wu, S.; Qin, W.; Ma, X.; Niu, Y.; Lai, S.; Yang, C.; Jiao, F.; Ren, L. Reductive leaching of gallium from zinc residue. Hydrometallurgy 2012, 113, 195-199. [CrossRef]

11. Liu, F.; Liu, Z.; Li, Y.; Liu, Z.; Li, Q.; Zeng, L. Extraction of gallium and germanium from zinc refinery residues by pressure acid leaching. Hydrometallurgy 2016, 164, 313-320. [CrossRef]

12. Liu, F.; Liu, Z.; Li, Y.; Wilson, B.; Lundström, M. Extraction of Ga and Ge from zinc refinery residues in $\mathrm{H}_{2} \mathrm{C}_{2} \mathrm{O}_{4}$ solutions containing $\mathrm{H}_{2} \mathrm{O}_{2}$. Int. J. Miner. Process. 2017, 163, 14-23. [CrossRef]

13. Xu, K.; Deng, T.; Liu, J.; Peng, W. Study on the recovery of gallium from phosphorus flue dust by leaching with spent sulfuric acid solution and precipitation. Hydrometallurgy 2007, 86, 172-177. [CrossRef]

14. Zhang, D.; Yang, S.; Yang, H.; Zhang, Y.; Zhang, S.; Li, Q. Experimental research on recovering gallium, iron and aluminium from corundum slags. Multipurp. Util. Miner. Resour. 1997, 3, 14-17.

15. Zhou, L. Rare Metals Metallurgy, 1st ed.; Metallurgical Industry Press: Beijing, China, 1988. 
16. Tian, Y.; Li, W.; Zeng, T.; Deng, H. Method for Recovering Gallium from Electric Arc Furnace Flue Dust of Corundum Production. CN Patent 1375564, 23 October 2002.

17. Li, W.; Lu, P.; Yin, Z.; Li, X.; Han, D.; Yang, Q. Method for Recovering Gallium from Corundum Flue Dust. CN 102676829A, 19 September 2012.

18. Fan, S.; Jia, Q.; Song, N.; Su, R.; Liao, W. Synergistic extraction study of indium from chloride medium by mixtures of sec-nonylphenoxy acetic acid and trialkyl amine. Sep. Purif. Technol. 2010, 75, 76-80. [CrossRef]

19. Yu, X.; Xie, G.; Wang, J.; Li, Y. Study on Indium Extraction in Acidic Medium. Yunnan Met. 2006, 35, $28-32$.

20. Li, H.; Wang, N.; Chen, Y.; Tian, Y. The Environmental Significance of the Removal of Corundum Dusts and the Mineralogical Study of Such Dusts. Acta Pet. Miner. 1999, 18, 348-356.

21. Xu, F.; Xu, N. Gallium production of three stage carbonization process. Henan Chem. Ind. 2002, 10, 21-24.

22. Sullivan, R.; Stern, W.; Vance, B. Process for Recovering Gallium. U.S. Patent 4193968, 18 March 1980.

23. Good, M.; Holland, F. Extraction of In(III) and Ga(III) from aqueous chloride media by long chain alkyl amines and quaternary salts. J. Inorg. Nucl. Chem. 1964, 26, 321-327. [CrossRef]

24. Good, M.; Srivastava, S. The nature of the halide complexes of Fe(III), Co(III), Ga(III) and In(III) extracted from aqueous chloride media by high molecular weight substituted alkyl ammonium compounds. J. Inorg. Nucl. Chem. 1965, 27, 2429-2436. [CrossRef]

25. Sato, T.; Nakamura, T.; Ishikawa, S. Liquid-liquid extraction of gallium (III) from hydrochloric acid solutions by organophosphorus compounds and high-molecular weight amines. Solv. Extr. Ion Exch. 1984, 2, $201-212$. [CrossRef]

26. Lu, F.; Xiao, T.; Lin, J.; Ning, Z.; Long, Q.; Xiao, L.; Huang, F.; Wang, W.; Xiao, Q.; Lan, X.; et al. Resources and extraction of gallium: A review. Hydrometallurgy 2017, 174, 105-115. [CrossRef]

27. Mihaylov, I.; Distin, P. Gallium solvent extraction in hydrometallurgy: An overview. Hydrometallurgy 1992, 28, 13-27. [CrossRef]

28. Yang, H.; Wang, W.; Zhang, D.; Deng, Y.; Cui, H.; Chen, J.; Li, D. Recovery of trace rare earths from high-level $\mathrm{Fe}^{3+}$ and $\mathrm{Al}^{3+}$ waste of oil shale ash (Fe-Al-OSA). Ind. Eng. Chem. Res. 2010, 49, 11645-11651. [CrossRef]

(C) 2018 by the authors. Licensee MDPI, Basel, Switzerland. This article is an open access article distributed under the terms and conditions of the Creative Commons Attribution (CC BY) license (http:/ / creativecommons.org/licenses/by/4.0/). 